\title{
A INFLUÊNCIA DAS FILOSOFIAS ALTERNATIVAS NA VIDA E NA LITERATURA DE J. D. SALINGER
}

\section{THE INFLUENCE OF ALTERNATIVE PHILOSOPHIES AND RELIGIONS IN J. D. SALINGER'S LIIFE AND WORK}

\section{Adolfo Jose de Souza Frota ${ }^{1}$}

Se uma pessoa bate palmas, ele consegue discernir o som. Ouça, então, o som de uma mão apenas.

Hakuin - mestre Zen

"Há uma paz maravilhosa em não publicar. É pacífico. Calmo.

Publicar é uma terrível invasão de minha privacidade. Gosto de escrever.

Amo escrever. Mas escrevo só para mim e para o meu próprio deleite".

Salinger - entrevista ao The New York Times

Recebido para publicação em 19/03/08

Aceito para publicação em 07/05/2008

\section{RESUMO}

O presente artigo tem por objetivo analisar a influência que as filosofias orientais como o Zen-Budismo, o Cristianismo Ortodoxo, o Taoísmo e o Hinduísmo teve (e ainda tem) na vida e na obra do autor norte americano J. D. Salinger: como essas religiões se tornaram fatores determinantes na temática da maioria dos seus contos.

Palavras-chave: Conto moderno. Filosofia oriental. Koan.

\begin{abstract}
This article aims at analyzing the influence eastern philosophies and religions like Zen-Buddhism, Russian Orthodox Christianity, Taoism and Hinduism may have had on J. D. Salinger's life and work and how these religions became the determining factor in the thematic choice of his short-stories.
\end{abstract}

Keywords: Modern short-story. Eastern philosophy. Eastern religions. Koan

1 Prof. M.Sc. de literatura em língua inglesa - UEG (Campos Belos - Goiás). Email: adolfo thedrifter@ yahoo.com.br e adolfothedrifter@gmail.com. 
É inegável que parte significativa da literatura de J. D. Salinger foi inspirada em algumas premissas da filosofia oriental, principalmente o Zen-Budismo. E que suas personagens, especialmente Seymour Glass, são os porta-vozes dessas metafísicas nas letras norte-americanas. Sem dúvida, Salinger, além de Herman Hesse, é um dos autores que mais procura retratar essa filosofia na forma como as personagens falam e agem, nas longas lembranças que Buddy tem do irmão morto, ou dos outros membros do clã ao se referir a algum problema que os aflige. Mas não somente suas personagens se comportam como adeptos do Orientalismo (Taoísmo, Hinduísmo, Cristianismo Ortodoxo russo e, principalmente, Zen-Budismo); Salinger também assim se comporta.

Se há uma tênue camada que separa a realidade da ficção, isso se realmente há alguma separação, o autor de $O$ apanhador no campo de centeio tem se mostrado também um representante Zen na forma como vem agindo desde que alcançou sucesso editorial. Analisaremos como se configura nos seus contos a religiosidade oriental e como Salinger tem se comportado, ou seja, vivendo recluso e em silêncio desde que se tornou um autor famoso, comportamento este que, conforme Dipti Pattanaik (2005), em texto online, apresenta um caráter "homilético", religioso.

A palavra Zen significa pensamento, meditação, a capacidade de ver e contemplar. É uma parte do Budismo mais anti-racional que se desenvolve na Índia e que também chega ao Japão. Ela se diferencia das outras crenças budistas por procurar a iluminação pela introspecção e intuição. E para o pensamento ocidental, esta filosofia se torna confusa e problemática. Isto porque não conseguimos aprender coisa alguma se não a colocarmos em palavras ou em algum sistema de sinais, como as fórmulas matemáticas e as notações musicais. Um mestre Zen chamaria essa característica de "conhecimento convencional", isto é, um sistema de abstrações, consistindo, além de sinais, símbolos em que as coisas e os eventos são reduzidos para os seus contornos gerais, de forma que possam ser compreendidos um de cada vez. Mas vivemos em um universo que não obedece a este sistema, um universo em que as coisas estão acontecendo todas ao mesmo tempo e cuja realidade não pode ser definida em termos abstratos (LUNDQUIST, 1991, p. 143-144).

A resposta Zen para esta problemática é que nós já sabemos de tudo sem saber e que aquilo que chamamos consciente, pensamento organizado, nada mais é do que uma mera função aquém da nossa consciência total. Por exemplo, acreditamos controlar as nossas vidas pela adoção de um papel social (professor, médico), mas a vida não funciona dessa forma. Nossos organismos funcionam normalmente sem precisarmos pensar neles: os batimentos cardíacos, cada respiração toma o seu curso natural mesmo que não percebamos. Além disso, costumamos ter uma visão convencional de nós mesmos como uma composição feita de memórias selecionadas. Para a filosofia Zen, nós somos aquilo que estamos fazendo no momento (LUNDQUIST, 1991, p. 144).

O silêncio literário do autor que não dá entrevistas há anos continua a ser um enigma tanto para os seus biógrafos quanto para os críticos. Warren French (1966, p. 30) diz que Salinger tem uma vida igual àquela com a qual Holden Caulfield tanto sonha, quando diz se fingir de surdo-mudo e esconder os filhos. Já James Lundquist (1979 apud PATTANAIK, 2005) revela que o seu longo silêncio como escritor e a sua insistência em manter-se longe da publicidade fez dele um escritor difícil de entender e ler com muita simpatia.

Dipti Pattanaik (2005) defende que o gesto de Salinger de silêncio e isolamento "pode ser parte de um extenso esforço para decretar em vida os valores que ele até agora problematizou em arte [...]. Além disso, ele é um dos poucos escritores modernos cuja arte e vida complementam cada um tão perfeitamente que um parece ser a extensão do outro".

Gurus, como Sri Ramakrishna e Swami Vivekananda, pregam que, através da renúncia dos frutos de trabalho, os homens se tornam seres divinos. Como aponta Ian Hamilton (1990, p. 130-134), a ordem de que ele almeja ser membro é a ordem baseada no talento, como se essa dádiva fosse a mesma coisa que iluminação. Partindo dessa premissa, percebemos que a família Glass 
se justifica. Salinger os cria como personagens talentosas, inteligentes e, ao mesmo tempo, ligadas às filosofias orientais e ao catolicismo místico. Essas religiões fornecem algumas respostas para a sua procura pela vida e pela expressão correta. $\mathrm{O}$ modo de vida contemplativo e de renúncias poderia, espiritualmente, contrabalançar os perigos de uma vida excessivamente materialista, como ocorria no século XX. Tal pensamento é consoante à filosofia Zen do Sansara e Nirvana. O Sansara é o mundo da ilusão e do sofrimento, mundo da matéria, da ambição, de tudo aquilo que pode tirar a alma (Átman) do caminho do Nirvana, ou seja, da verdade, da iluminação, do conhecimento e redenção. No embate entre os dois mundos, a maioria dos filhos de Bessie Glass escolhe o caminho da iluminação, absorvendo filosofias do hemisfério oriental, como o Zen-Budismo e o Hinduísmo ou resgatando o Cristianismo Ortodoxo Russo, pela leitura do The Way of a Pilgrim and the Pilgrim Continue His Way (O caminho do peregrino e o peregrino continua o seu caminho).

O fato de Salinger ter contato com os textos de Sri Ramakrishna e Swami Vivekananda fez ele passar a se ocupar com uma vida de reclusão e isolamento, à maneira de um monge. $\mathrm{O}$ estilo de vida vedântico que os autores pregam visualiza dois principais modos de conduta: a vida de um chefe de família (cívica, social) e a de sannyasin (devotada à oração). Ambos os estilos têm diferentes estados de perfeição. Salinger adota um estilo de vida que o aproxima de uma existência menos materialista e mais espiritualista. O seu silêncio, assim como o silêncio de Seymour Glass, que fala através das vozes dos irmãos, é um importante ingrediente de disciplina espiritual como um sinal de isolamento do furacão, ou seja, da atividade materialista que fomenta o aprisionamento do ego, de uma procura pela consciência além do imediato e periférico sentido de apreensão e a possibilidade de aquisição de uma consciência mais elevada que pode somente ser transmitida para o iniciado e pode cair no senso comum pela insinceridade diária da palavra.

Sri Aurobindo (1970 apud PATTANAIK, 2005) prega que o silêncio interior da mente pode fazer com que o conhecimento apareça, venha à tona, pois as atividades mentais só criam perfeições superficiais e representações que não são o conhecimento verdadeiro. E o discurso é, geralmente, a expressão da natureza superficial. Salinger, ciente dessas idéias Zens, assimila o conhecimento e passa a se comportar à maneira dos monges, recluso em sua solidão e distante do mundo material e da fama. O mesmo podemos creditar a Seymour, que não aparece fisicamente em boa parte dos contos do autor, e que se faz ouvir em apenas dois momentos: no conto "Um dia ideal para os peixes-banana", nos seus momentos finais, e em "Hapworth 16, 1924", a última publicação de Salinger até o momento, e que traz Seymour no outro extremo da vida. Essa discussão sobre os extremos fama e reclusão, isolamento e presença ocorre com freqüência em "Zooey" (Franny \& Zooey - FZ). Bessie, mãe dos irmãos Glasses, conversando com Zooey, reclama:

- Às vezes sinto vontade de esganar o Buddy por não ter arranjado um telefone [...]. Isso é tão desnecessário? Como pode um adulto viver daquele jeito... sem telefone, sem nada? Ninguém pretende invadir sua vida privada, se é isso que ele teme. Mas certamente não acho que seja necessário ele viver como um eremita $(F Z$, p. 63 , grifo do autor).

O isolamento, que já vinha desde Seymour (morto) e se tornara um fator comportamental de Buddy (e de Salinger também) prossegue com os membros mais jovens da família. Fato curioso é que os irmãos Glasses fazem, na infância, parte de um programa de rádio chamado "Menino esperto" (It's a Wise Child), ou seja, desde cedo têm que lidar com a fama. E sofrem, pelo menos para eles, deste mal. Em um momento, tanto os irmãos quanto Salinger lidam com a fama. Salinger, ao pelo menos nos primeiros contos, aqueles que nunca foram publicados em coletânea, como "Slight Rebellion Off Maddison", lutava por um espaço de destaque entre as revistas. Segundo Zooey, tanto ele quanto Franny padecem do complexo do "Menino esperto". Eles não conseguem sair do ar:

Não falamos, discursamos. Não conversamos, expomos. Pelo menos, eu sei que sou assim. Desde o primeiro minuto em que entro numa sala qualquer e dou com alguém que tenha o número habitual de 
orelhas, viro logo um vidente ou então fico mudo (FZ, p. 111, grifo do autor).

O desejo de auto-reclusão se torna presente assim tanto no autor Salinger quanto nas suas personagens. $\mathrm{O}$ caso de Seymour é mais radical, visto que a personagem principal quase não aparece fisicamente. Essa característica faz parte de uma atitude budista, o silêncio e a vida eremita são preceitos da religião como um mecanismo que auxilia a busca do conhecimento. Além do Zen-Budismo, Salinger foi fortemente influenciado pela cultura japonesa, que se aproxima muito das religiões advindas da Índia. O corolário da postura japonesa sobre a língua poderia ser chamado de "estética do silêncio", segundo a qual o homem é capaz de alcançar o nível mais elevado de evolução somente quando não se utiliza da superficialidade da linguagem verbal. Desta forma, deduz-se que a atitude de Salinger assim como a de sua personagem mais complexa, Seymour, vem ao encontro da atitude Zen da preservação da interioridade, do silêncio e isolamento como forma de atingir a verdade universal.

Alcançando sucesso com as suas publicações, torna-se estranho que um autor de êxito do porte de Jerome David Salinger de uma hora para outra se isole do mundo, se recuse a dar entrevistas e até mesmo publicar prováveis novos livros. Esse comportamento encontra ressonância na religião indiana. Na filosofia oriental há uma figura chamada sadhaka, ou seja, aquele que procura a perfeição. E a perfeição é atingida quando o sadhaka, voluntariamente, se nega a ambicionar qualquer bem do mundo. Para Salinger, o sucesso artístico, para Seymour, a glória de ser gênio e, para Franny, uma promessa como atriz, a adulação do meio teatral. Além dessa característica Zen que se configura tanto na vida real quanto na arte, o sadhaka deve se abster de relações sexuais (Brahmacharya), negar os benefícios materiais (aparigraha) e eliminar a identidade individual (apaurusheya). Teddy (do conto homônimo do livro Nove Estórias - NE), por exemplo, caiu na lei da transmigração espiritual quando foi seduzido por uma mulher e Franny detesta o assédio artístico.

O conto "Teddy" é aquele em que o discurso Zen é mais presente. Ele também se torna o marco inaugural dessa nova temática. Em conversa com Bob Nicholson, o Jatismara Teddy (aquele que conhece as suas vidas anteriores) se lembra que em sua última vida era um iogue hindu que se afastou da graça de Deus por sua susceptibilidade para com a luxúria: "Está certo [...]. Eu conheci uma senhora e praticamente parei de meditar" (NE, p. 158). Segundo a lei kármica, não apenas a impureza sexual, mas qualquer tipo de ação ou contemplação de uma ação realizada com o intuito egoísta pode provocar a queda do homem, o impedimento que ele se una a Deus. O seu nascimento na América se torna um efeito punitivo quando ele cai em pecado.

Para Pattanaik (2005), o que Salinger deseja em suas obras está acima do âmbito da linguagem ficcional. É a perfeição que está além do reino humano e da linguagem que pode ser apenas comunicada através do silêncio, a forma como os mestres zens ensinam o conhecimento espiritual para os seus discípulos. Esse mesmo silêncio podemos observar em Seymour, que deixou um espólio familiar (cartas, diários e poesias). Suas palavras são conhecidas apenas por alusões de Buddy, Franny e Zooey, pois Seymour só aparece falando sobre sua religiosidade em "Hapworth 16, 1924". E o conjunto de poesias do Glass morto, que juntas dariam um livro, foi proibido de ser publicado pela esposa Muriel. Ou seja, tanto Salinger quanto suas personagens conseguem, de alguma forma, ter pontos em comum. É só lembrarmos que vários contos salingerianos estão fora de catálogo pela própria imposição de seu autor. Se o nome de sua personagem mais complexa pode gerar várias interpretações que denotem o seu caráter (a pronúncia do nome Seymour, fonologicamente pode significar ver mais, por exemplo), a atitude espiritual, pelo contrário, designa a sua escolha de falar menos. E o silêncio do autor de Franny \& Zooey se torna o gesto culminante quando sua vida se torna a mensagem, um testamento de valores que ele até agora professa.

Ainda falando do conto "Teddy", que apresenta a personagem Teddy em um cruzeiro com a família, o jovem prodígio defende a idéia de que tudo que o rodeia faz parte de uma grande Força Cósmica e Universal. Esse discurso resgata a crença na natureza divina de todas as coisas e seres: 
Eu tinha seis anos quando vi que tudo era Deus, e fiquei todo arrepiado e tudo isso. Me lembro que foi num domingo. Naquela época minha irmã era uma criancinha pequena e estava tomando leite; de repente eu vi que ela era Deus e o leite era Deus. Quer dizer, o que ela estava fazendo era verter Deus em Deus (NE, p. 159, grifo do autor).

Tal pensamento é consoante com a filosofia Zen que prega serem todas as coisas manifestações divinas. O teor Zen deste conto assemelha-se muito ao romance Sidarta, de Herman Hesse, que conta a peregrinação desse jovem em busca da iluminação. Em conversa com o amigo e discípulo Govinda, Sidarta fala a respeito da nossa natureza divina:

O pecador não se encontra a caminho do estado de Buda; não está em plena evolução, muito embora o nosso cérebro seja incapaz de imaginar as coisas de outro modo. Pelo contrário, no pecador já se acha contido, hoje, agora mesmo, o futuro Buda [...]. O mundo, amigo Govinda, não é imperfeito e não se encaminha lentamente rumo à perfeição. Não! A cada instante é perfeito. Todo e qualquer pecado já traz em si a graça. Em todas as criancinhas já existe o ancião (HESSE, 2003, p. 118).

Mais adiante, Sidarta fala que uma pedra pode ser terra e da terra pode se transformar em planta, ou num animal, ou num homem, e pode ser Deus e Buda (Sidarta, p. 118). Esta é a confirmação de um preceito Zen da Unidade com Deus, em que cada membro da natureza, cada representante da força vital é uma centelha da Força Cósmica, da Suprema Sabedoria. Por este motivo, o romance se torna um clássico na era hippie e ganha popularidade entre aqueles jovens.

Teddy também tem preferência pela meditação, apesar de, para ele, ser difícil meditar e levar uma vida espiritual na América, que despreza o sentimentalismo e a interioridade (NE, p. 159). Numa das partes mais interessantes do conto, ele fala que devemos "vomitar" a maçã que todos comemos, diferentemente de Adão e Eva, para poder ver as coisas como elas realmente são. A maçã, para a concepção cristã, representa o conhecimento científico que se torna prejudicial na busca pela evolução. "A lógica é a primeira coisa que você tem que abandonar" (NE, p. 160), aconselha o jovem prodígio que conversa com Bob Nicholson. Ele também adverte um professor que o entrevista para parar de ensinar, já que ele leciona muitas coisas que não lhe são benéficas e nem para os seus alunos (NE, p. 162). Esta parte do conto também se assemelha muito às palavras de Sidarta, que diz não conseguir vencer o seu outro eu por ter um excesso de erudição, de versículos sagrados, de rituais, ambições e ascetismo (Sidarta, p. 83-84).

Os conselhos de Teddy se aproximam do modelo de educação vedântica, pois ele quer fazer as pessoas compreenderem o caráter ideal, supremo, que o Baghavad Gita diz ser o Sthitaprajna, o ser sem nenhum tipo de indulgência sentimental ou paixão. Aquele que pode ter um melhor controle do imediato transcendendo-o. Essa idéia é mais bem desenvolvida em “Zooey”. Zooey, em conversa com Franny, num momento decisivo para a irmã, diz: Desprendimento, companheira. Ausência de desejo. 'O fim de todas as ambições, de todos os anseios'. Esse negócio do desejo [...] é o que faz um ator, em primeiro lugar" (FZ, p. 155).

O crítico James Lundquist (1991, p. 143) afirma que é em Nove estórias que a filosofia Zen é mais propositadamente utilizada como uma força conceitualizante. Quando o leitor se propõe a ler a coletânea, as primeiras palavras de Salinger são um koan budista que abre o livro: "Nós todos conhecemos o som de duas mãos que aplaudem. Mas qual será o som duma única mão que aplaude?", é a pergunta feita. $\mathrm{O}$ leitor mais atento talvez tente respondê-la assim que termine o livro. Este koan, importante para auxiliar na busca do conhecimento, é um dos mais famosos e é atribuída ao poeta japonês Hakuin (1685-1768). Lundquist (1991, p. 143-145) aponta que o koan utilizado por Salinger é um exercício de primeiro nível (Hosshin) numa escala de atividades, em busca da iluminação, que vai até o sexto.

O koan serve para que o aspirante à iluminação medite sobre a pergunta contida e só volte ao mestre que a fez quando souber e conseguir provar o significado da inquirição. É um processo utilizado para que se produza o satori (compreensão espontânea) e a comunhão com a verdadeira realidade da natureza humana e que não pode ser descrita por palavras. É uma forma de penetrar o nevoeiro da 
abstração e, portanto, não pode ser explicado por qualquer abstração. A metáfora serve para que o discípulo Zen, a princípio, chegue à conclusão de que não sabe absolutamente nada, tudo se torna incompreensível assim como o som de uma mão. Da mesma forma que não conseguiria mover uma rocha de gelo, ele não consegue compreender a metáfora. Mas, depois de um tempo indeterminado, o gelo começa a derreter e o estudante passa a ter noção do significado e o nó é desembaraçado, a abstração da mente que procura se conhecer é malograda, não mais existe. Quando ele chegar a este estágio de liberação, seu mestre pode começar o seu treinamento.

Aquela oferecida pelo garoto genial Teddy, a de vomitar a ciência, impele o leitor a um efeito que o koan sugere, ou seja, se desligar da lógica. Porém, o exercício do koan Zen pode levar, segundo Heinrich Dumoulin (1970 apud GOLDSTEIN; GOLDSTEIN, 1987, p. 82), ao desastre, visto que a supressão antinatural da razão é perigosa, pois tende a destruir, permanente e irremediavelmente, a estrutura psíquica de uma pessoa. E uma abordagem, levando-se em conta tal premissa, ajuda-nos a entender Seymour em "Um dia ideal para os peixesbanana”. Dessa forma, o anti-racionalismo pode levar a um colapso mental, porque a razão se tornaria parte importante da constituição do ser humano, e, sem esse componente, o homem pode estar fadado à morte, como foi o caso de Seymour.

Com isso, o exercício Zen de tentar ouvir o som do aplauso de uma única mão pode levar o praticante dessa filosofia ao discernimento de um som inaudível para os ouvidos, pode ultrapassar todo o conhecimento, deixar o mundo das distinções para trás, atravessar o oceano kármico dos renascimentos e vencer a escuridão da ignorância. A iluminação que o discípulo alcança o conduz para uma liberdade ilimitada.

Se pensarmos em algo que possa simbolizar essa liberdade ilimitada, a criança se adequaria perfeitamente à idéia. Para as mentes ocidentais, a liberdade ilimitada é mais facilmente simbolizada pelas crianças por elas agirem de forma natural, ainda não subjugadas pelas convenções sociais. As crianças personificam o estado religioso da per- feição. Nas últimas histórias salingerianas, elas se aproximam de um sentido de unidade primária. Por isso, o autor as elege como os modelos autênticos. Nas crianças, a imaginação ainda não foi destruída pelos pais exigentes, elas ainda não racionalizam suas ações. Elas também deixam manifestar suas espontaneidades tão facilmente quanto o ato de respirar e não dicotomizam a linguagem, as pessoas e os lugares. Por fim, basta lembrarmos de um ditado budista que diz ser a mente da criança a mente de Buda, e a passagem bíblica de São Mateus (cap. 19 , v. 14) em que Jesus diz serem elas pertencentes ao Reino dos Céus, para compreendermos a razão sagrada da escolha das personagens de Salinger.

Em Nove estórias, aparecem Sybil Carpenter ("Um dia ideal para os peixes-banana"), Lionel Tannembaum, sobrinho de Seymour ("Lá embaixo, no bote") e Seymour Glass, que não consegue se adaptar ao mundo e às responsabilidades dos adultos. Em "Carpinteiros, levantem bem alto a cumeeira", do livro Carpinteiros, levantem bem alto a cumeeira e Seymour, uma apresentação - CS, a dama de honra do casamento alega que a fuga de Seymour da responsabilidade do casamento acontece por ele nunca ter crescido (CS, p. 39). Em "Zooey", Buddy se refere a uma garotinha que havia lhe chamado a atenção por ter dado uma resposta Zen a uma pergunta feita por ele. A pergunta se refere à quantidade de namorados que a garotinha tem, e a sua resposta foi dois, um menino e uma menina. A impressão foi para Buddy tão benéfica que assim ele se refere ao encontro: "uma visão perfeitamente comunicável da verdade" (FZ, p. 56).

Menos enigmática do que Nove estórias é "Franny", que, à parte das polêmicas sobre essa personagem ser a mesma que aparece em "Zooey", apresenta o Cristianismo Ortodoxo como a esperança da irmã caçula dos Glass vencer a crise nervosa, provavelmente em decorrência de ela atravessar o limiar entre o mundo infantil e o mundo adulto, mesmo limiar que Holden e Seymour se recusam atravessar. Os dois contos reunidos em Franny \& Zooey são, para George Panichas (1991, p. 157) "um outro exemplo de como a ficção moderna pode afirmar a divindade de todos os homens". Em "Zooey", a crise é vencida quando Zooey tem um longo 
diálogo com a irmã, lembrando-a de várias frases de efeito proferidas por Seymour. Nestes dois contos, há a forte presença de uma narrativa russa antiga, datada do século XIX, anônima e encontrada em um monastério grego ortodoxo: The Way of a Pilgrim and the Pilgrim Continue His Way. Franny procura nessa obra um meio de redenção e de sabedoria para, provavelmente, ajudá-la nessa travessia.

A narrativa The Way of a Pilgrim... traz a longa peregrinação de um camponês pelo interior da Rússia em busca do conhecimento espiritual e da salvação. Certa vez, ela ouve de um pregador que o caminho para a elevação está nas palavras de São Paulo aos Tessalonicenses: "Orai sem cessar". Ao iniciar a viagem, ele encontra um monge ancião que lhe ensina como conseguir orar sem cessar e o que é a "Oração do Senhor". Para atingir a graça, ele tem que estudar o Philokalia (uma coleção de escritos religiosos originalmente em grego realizados pelos padres entre o quarto e o décimo quinto século). $\mathrm{O}$ monge se refere à "Oração do Senhor" como um chamar contínuo e ininterrupto pelo nome sagrado de Jesus Cristo com os lábios, mente e coração, e na ciência de Sua duradoura presença é um pretexto para a sua bênção em todos os empreendimentos, em todos os lugares e em todas as horas, mesmo dormindo.

Com a explicação do monge, o peregrino descobre o conteúdo da oração, ou seja, a repetição contínua das palavras "Senhor Jesus Cristo, tenha piedade de mim!”. Com a peregrinação e leituras, o camponês gradualmente descobre como orar sem cessar, e, por isso, acaba alcançando o estado de felicidade e inocência, a liberdade sobre o pensamento maléfico e sobre a consciência egoísta. Em sua viagem árdua e em seu encontro com todos os tipos de pessoa, o camponês alcança o sucesso da vida contemplativa, porque a "Oração do Senhor" se transforma numa parte orgânica de sua vida e o seu propósito, capacitando-o para ver e sentir Deus em todos os lugares. Esse se torna o principal ensinamento do livro e percebemos Franny tentando levar uma vida semelhante ao do peregrino na esperança de que ela consiga o mesmo insight espiritual.

Para Anne Gael Henningfeld (2005), a crise foi provocada pelo sofrimento de Franny por ela viver em um mundo egoísta e por ela detestar o egoísmo acima de tudo, e a leitura da história mística significa um desprendimento de si mesmo, uma perda do egoísmo. Ao entoar o nome de Deus, o suplicante foca somente n'Ele. A repetição da oração faz o homem se desprender de sua individualidade. Nessa parte, a idéia de TheWay of a Pilgrim... assemelha-se à filosofia Zen do desprendimento do materialismo e da consciência individual.

Segundo John Wenke (1991, p. 73), o clímax de "Franny" ocorre quando ela e o namorado Lane Coutell conversam sobre a eficácia de um meio alternativo de vida. A obsessão da caçula dos Glasses apresenta, num literário e religioso paradigma, um corretivo em potencial dos horrores egoísticos. O livro, que ela primeiramente afirma ter descoberto numa aula de religião, em "Zooey", o irmão diz pertencer a Seymour. A "Oração do Senhor", que causa em Franny uma descoberta metafísica, também oferece um antídoto para o embaraço do ego. A oração, diz Franny, se torna autoprogressiva, pois algo acontece:

E as palavras ficam sincronizadas com as batidas do coração e é então que uma pessoa se encontra realmente rezando sem parar - quase sem se dar por isso - o que tem um efeito esmagadoramente místico em todas as nossas concepções" (FZ, p. 34).

Assim, Franny acredita que o hábito da repetição acaba se tornando qualidade por si só.

A "Oração do Senhor" reflete, ao mesmo tempo, o desejo de Franny de preenchimento espiritual e um perigoso sintoma de instabilidade mental. E nessa dualidade reside o perigo, já que "apagar" a essência de alguém com uma oração autoprogressiva, acaba eliminando a sua própria identidade. John Wenke (1991, p. 74) diz que esta condição não deveria "ser entendida como o objetivo dos sobreviventes Glasses, mais notadamente Franny, Zooey e Buddy. Antes, o que um faz com identidade pessoal é o tortuoso dilema pelo qual eles lutam".

"Zooey", que se torna a continuação direta de "Franny", apresenta a sequiência dos eventos após o encontro da irmã com o namorado. Já em casa, Franny se fecha em seu mundo, e isso preocupa Bessie, a mãe, que pede para que Zooey intervenha. A 
narrativa, que traz o efeito da crise na caçula Glass, também apresenta algumas referências das experiências de Buddy. Uma delas, que chama atenção, é o encontro dele, já referido, com uma garotinha que disse ter dois namorados, um menino e uma menina. A referência a esse encontro fortuito fez Buddy se lembrar de um ensinamento Zen uma vez proferido por Seymour. O Irmão morto certa vez disse: "que todo estudo religioso legítimo deve culminar na ignorância das diferenças, as ilusórias diferenças, entre rapazes e moças, animais e pedras, dia e noite, calor e frio" ( $F Z$, p. 56).

O grande momento de "Zooey" é o diálogo entre os irmãos Franny e Zooey. O ponto fundamental deste conto se desenvolve quando Zooey revela todos os problemas com a educação que recebera, tanto por parte da escola quanto por parte até dos próprios irmãos (Seymour e Buddy). Referindo-se aos dois mais velhos, chama-os de bastardos por terem se tornado, tanto ele quanto Franny, excêntricos e anormais (FZ, p. 110). Entretanto, Franny reconhece que a solução para os danos causados pela escola seriam amenizados a partir da escolha de preceitos Zens:

Por vezes, penso que o saber... quando é saber por saber e nada mais do que isso... é o pior de tudo [...]. - Eu não creio que tivesse ficado tão deprimida se uma vez por outra... sim, apenas uma vez por outra... houvesse alguma delicada e mínima implicação, uma sugestão mesmo superficial, de que o conhecimento deve conduzir fatalmente à sabedoria e que, se não o fizer, é uma repugnante perda de tempo! Mas lá [universidade] nunca houve disso ( $F Z$, p. 116, grifo do autor).

Esclarecendo o motivo pelo qual Franny não consegue assimilar de forma completa os ensinamentos do The Way of a Pilgrim..., Zooey lembra que a intenção da "Oração do Senhor" é dotar as pessoas da consciência de Cristo e não colocá-las em um lugar sagrado e aconchegante com alguma personagem divina e adorável, que iria levá-la em seus braços e aliviá-la de suas obrigações e que expulsaria o professor Turper (seu desafeto) de sua presença: "A oração tem uma finalidade e só uma finalidade. Dar à pessoa que a recita a Consciência de Cristo" (FZ, p. 134).
Zooey reconhece a importância da "Oração do Senhor" como o meio de atingir a fusão entre o homem e Cristo, fazendo com que o ego desapareça, mas não descarta o apoio do Zen-Budismo para fortalecer as convicções de Franny. Este livro de Salinger nos soa como mais um rito de passagem da irmã caçula dos Glasses, que se vê em dúvida sobre o modelo de metafísica que a auxilie na dura passagem. Conhecendo The Way of a Pilgrim..., sente falta do guia espiritual, o guru, falta Seymour ou alguém que o represente. E é Zooey quem toma o lugar em sua ausência. É ele quem a ajuda a "traduzi-lo", a reconhecer os problemas de sua interpretação empírica. Desta forma, Zooey aconselha a irmã: "Você pode dizer a Prece de Jesus daqui até ao dia do Juízo, mas se você não percebe que a única coisa que conta na vida religiosa é o desapego, o desprendimento, então não vejo como conseguirá avançar um palmo" ( $F Z$, p. 154-155).

A leitura e a repetição da "Oração do Senhor" por Franny denotam sua vontade de alcançar a iluminação espiritual, mas, intelectualmente, vê o seu desejo por satisfação pessoal entrar em conflito com a sua moral. Zooey lhe sugere aderir à idéia Zen de desapego ao materialismo, do desinteresse e da cessação de qualquer desejo. Para Anne Gael Henningfeld (2005), esta filosofia serve para que o homem limpe a mente das idéias pré-concebidas e, agindo dessa forma, ele conseguirá a sabedoria. É um processo que vai de encontro à educação tradicional que abarrota os estudantes com o conhecimento. Franny reclama que os "poetas" de sua universidade não escrevem nada de belo, apenas forçam-na a aprendê-los.

Para Panichas (1991, p. 159), a escolha do The Way of a Pilgrim... não deve ser concluído como uma conversão do autor de Nove estórias ao misticismo russo, pois a abordagem percebida pela leitura do livro Franny \& Zooey é inteiramente não sectária, é principalmente uma busca pelo sentido religioso e pela visão espiritual nos mais altos níveis de experiência. Este livro não constitui um manual de devoção e sim uma obra de arte criativa que transcende a doutrina religiosa, o credo e as dimensões teológicas. A obra trata da sensibilidade, das emoções vitais e respostas. Qualquer tentativa de 
tratar a obra do plano religioso deve ser destacada da severidade teológica e homilética. Na verdade, o que distingue este livro é a religião, e não a religiosidade.

"Carpinteiros, levantem bem alto a cumeeira", conto sobre o dia do casamento de Seymour e Muriel e da fuga dos noivos, também é outra narrativa na qual encontramos várias referências à doutrina Zen e Taoísta. Fica evidente que quanto mais Salinger mergulha no estudo desses princípios religiosos alternativos, mais transparece sua verticalização para esse assunto. A partir do Cristianismo Ortodoxo russo, imergimos no Hinduísmo e Zen-Budismo pelos discursos das personagens envolvidas, a partir de Nove estórias. No conto que analisaremos a partir de agora, além de Buddy, como narrador e personagem e Seymour (como uma voz), outros seres ficcionais aparecem como novos elementos que simbolizam o pluralismo religioso de J. D. Salinger.

No discurso de Buddy Glass, percebemos como se configura o conhecimento desse autor nas referências que o narrador faz de sua formação e da formação espiritual do irmão: "Não sei se seria oportuno esclarecer que meus vínculos - com a filosofia oriental, tanto quanto os de Seymour, estavam e estão enraizados no Velho e no Novo Testamento, no Advaita Vedanta e taoísmo clássico" (CS, p. 177).

"Carpinteiros..." começa com um evento passado em 1934, quando Franny (10 meses de idade), com caxumba, passa a noite com Buddy e Seymour. Acordando com o choro da caçula, Buddy presencia o irmão lendo em voz alta um texto taoísta do poeta chinês Lieh-tzu. O texto, assim como o diário do Glass morto, que aparece mais adiante, são os elementos principais que ajudam a elucidar o texto todo. A parábola conta a história do duque Mu que pede a Po Lo, seu experiente perito em cavalos, um novo ginete. Po Lo diz que um bom cavalo pode ser distinguido pela sua constituição física. Porém, um cavalo fora de série, aquele que não levanta poeira e não deixa rastros, é algo imperceptível e veloz, esquivo como o ar. Visto o duque estar interessado no animal, o perito recomenda que ele procure Chiufang Kao, que, despachado para um lugar remoto, depois de três meses, encontra-o. Kao descreve o animal como uma égua baia. Entretanto, quando chega um garanhão negro como carvão, Mu reclama a Po Lo que Kao não podia nem mesmo distinguir cor e sexo. Encantado, o perito responde que Kao é dez mil vezes melhor que ele porque tem em mente apenas o lado essencial, espiritual. Ao fazer prevalecer apenas o que interessa, Kao se esquece dos meros detalhes, julgando apenas as qualidades internas e se esquecendo do aspecto externo.

A parábola de Lieh-tzu visualiza o homem vivendo sob os princípios taoístas, o caminho celestial de perfeita liberdade e harmonia com a natureza, em que ele perde a auto-consciência e se torna tão suave quanto a água, tão livre quanto uma criança, tão informe quanto um bloco de madeira. Entrando no vazio sem limite, forma ou nome, ele perde qualquer identidade prévia como um ser separado. Vazio do falso ego, com todos os seus desejos e ilusões, ele conseguirá divisar o verdadeiro caminho. Desta forma, o homem que se "perde" no Taoísmo tem a liberdade espiritual de divisar o cavalo excepcional, pois somente um visionário ignoraria cor e sexo, os padrões do critério humano, para julgar sob a luz Tao. A parábola também celebra o reino do espírito e introduz a preocupação de Seymour com as qualidades internas. E, finalmente, ela serve para associá-lo com a religião oriental.

A análise de Dennis O'Connor (1987, p. 122), em "Salinger's Religious Pluralism: the Example of 'Raise High the Roof Beam, Carpenters"', da qual aproveitaremos algumas referências, discorre sobre três personagens que se destacam. A primeira delas é Kao, que atua na parábola taoísta. A segunda, Seymour, o irmão ausente, e a outra, o velho misterioso e inominado que vai para o apartamento dos Glasses. Segundo O'Connor (1987, p. 122), estes três "visionários" sugerem a profundidade religiosa que tempera a narrativa de Buddy e que concentra os temas da visão falsa contra a verdadeira, a exigência social opressiva por uma "normalidade" versus o não categórico estilo de vida do artista visionário sob a filosofia taoísta. Na filosofia Tao, o agir pelo não agir é conhecido pelo termo wu-wei, ou seja, agir de forma natural e espontânea. Assim, o seu agir parece vazio e sem forma, não produtivo como as nuvens passageiras. Essa característica pode ser 
observada no jeito como ele se comporta com sua noiva e com a família dela:

Quando estávamos sentados na sala de visitas, a familiaridade entre M. e sua mãe me impressionou como alguma coisa muito bonita. Elas conhecem as fraquezas uma da outra [...] e se criticam com os olhos. [...] Quando discutem entre si, não há o menor perigo de que se crie uma discórdia permanente, porque são Mãe e Filha. É um fenômeno ao mesmo tempo terrível e belo de se assistir. Todavia [...] há momentos em que desejo que o sr. Fedder tivesse uma participação mais ativa na conversa (CS, p. 62).

A tranqüilidade de Seymour, que causa estranhamento para a família e para os críticos, indica mais uma evidência taoísta no conto. Dessa forma, a tranqüilidade adquire um sentido que outra interpretação diria ser estranha. $\mathrm{O}$ autor oferece um indício taoísta na primeira anotação do diário, quando Seymour contrasta a sua serenidade com a dos soldados desmaiando de frio: "Eu não tenho circulação nem pulso [...]. O andamento do Hino Nacional e eu estamos em perfeita sintonia. Para mim, seu ritmo é o de uma valsa romântica" ( $C S$, p. 60).

A serenidade de Seymour evoca uma tranqüilidade meditativa, de harmonização entre o homem e o ambiente, de total desligamento para assuntos exteriores. A sua paz pressupõe um desinteresse flexível que supere todos os obstáculos, como foi a guerra. Assim, o crime denunciado pelo psiquiatra em Nove estórias, a respeito da liberação de Seymour do hospital do exército, se torna uma interpretação pessoal dele (psiquiatra) e da família da noiva, apenas uma versão que procura explicar o estranho comportamento da personagem.

Uma das personagens que chama a atenção de O'Connor (1987, p. 125-127), no artigo citado anteriormente, é o homem misterioso que vai à casa de Buddy. Sua única identificação é o parentesco com Muriel. Na verdade, ele é o tio do pai da noiva. É descrito apenas como um surdo-mudo, cujo silêncio só ressalta a aflição tumultuosa dos outros convidados. A descrição desta personagem também se adequa ao preceito taoísta do homem perfeito que não se constitui como ser. Sendo inonimado, ele não tem ego, identificação. Mudo e desinteressado, ele sugere tanto o esquecimento de Kao das coisas inessenciais quanto à presença "espectral" de Seymour, o hai-yen, expressão Tao que significa "liberdade das palavras", o estado daquele sem nome e sem ego. Esta personagem também se mostra uma pessoa inerte e serena, mesmo no clima das declarações pesadas da dama de honra. A inércia é prescrita na filosofia Tao. Para a inércia do céu, chama-se pureza, a da terra, paz.

O conto "Seymour: uma apresentação" é a justificativa de Buddy para o suicídio do irmão. Um dos temas mais notáveis na literatura de Salinger é a da falha do poeta em sobreviver no mundo moderno. Seymour havia composto 184 haicais, e Buddy discute a influência do verso japonês e chinês na composição dos mesmos. John Wenke (1991, p. 103) nos informa que o haicai, forma favorita do Glass morto, "fornece um veículo de iluminação espiritual, especialmente na preocupação de Seymour com a invocação da espiritualidade intrínseca de todas as pessoas e coisas". Para Salinger, o poeta se torna um canal para o mundo espiritual ser expresso: "o verdadeiro poeta não escolhe o seu material. $\mathrm{O}$ material sem dúvida o escolhe, não o oposto" ( $C S$, p. 105).

Em certo momento, Buddy se volta para considerações da força da filosofia Zen e do combate contra as tradições ocidentais. Nas palavras de Buddy, a verdadeira força Zen sobrevive às impressões equivocadas que as mentes ocidentais têm de seus ensinamentos. Esse depoimento, quase no final da narrativa, parecer-nos-ia uma despedida do tema religião se não houvesse outra publicação posterior à "Seymour: uma apresentação":

[...] o verdadeiro zen certamente sobreviverá a seus paladinos ocidentais, os quais, na sua grande maioria, parecem confundir a quase-doutrina do Desligamento com um convite à indiferença espiritual, até mesmo à insensibilidade - e que evidentemente não hesitariam em derrubar um Buda sem antes fazer por merecer um punho de ouro. O genuíno zen, escusado dizer - mas é melhor dizer, no ritmo em que vou seguindo -, estará por aqui depois que sujeitos pretensiosos, como eu, já tenham há muito desaparecido. (CS, p. 176-177).

O último conto de Salinger, "Hapworth 16, 1924" é uma divagação, um prefácio de 20 mil 
palavras para o silêncio. O jovem Seymour, curiosamente mais evoluído do que o outro de "Um dia perfeito...", reforça a sua força espiritual ao falar sobre temas como a reencarnação e o conhecimento aprofundado das religiões. Seymour também critica o conhecimento estreito dos médicos, ou seja, da ciência, afirma conhecer sua trajetória espiritual e pede uma longa lista de livros, abrangendo várias áreas do saber, principalmente literárias e espirituais. O conto é mortalmente chato, quase ilegível e não conseguiria prender o leitor que se entusiasmou com as outras narrativas. Em suma: o Seymour de "Hapworth 16, 1924" é semelhante ao Teddy de Nove estórias. As referências ao Zen-Budismo são praticamente as mesmas, parecendo-nos que em "Hapworth..." estão um pouco mais desenvolvidas. De qualquer forma, quem leu e compreendeu "Teddy" não terá dificuldade com este conto, a não ser o fato de que é uma carta extensa, difícil e contraditória, pois, pela idade de Seymour, sete anos, torna-se improvável que uma criança tenha tamanha erudição, escreva de forma tão complexa em tão tenra idade.

$\mathrm{Na}$ verdade, acreditamos que o sentido do conto repousa na decisão de Seymour de se retirar das relações com os humanos. Sendo isso, vida e ficção estão intimamente relacionadas, visto que há quarenta anos não temos notícias de novas publicações do autor. O ultimato de Seymour, ou seja, o seu silêncio representa o silêncio do próprio Salinger. "Hapworth 16, 1924" contém as palavras finais do jovem mestre, suas últimas recomendações e pensamentos, a não ser que Salinger ainda publique algo novo. De qualquer forma, parece ser uma despedida da família, dessa temática religiosa ou mesmo da vida de escritor. São apenas meras suposições reforçadas pelo longo silêncio do autor e pelo seu repúdio sempre crescente à publicidade.

Sendo Seymour o guru de uma família, que pregou os ensinamentos de diversas religiões orientais para os irmãos, pareceu-nos ter falhado ao não conseguir viver de acordo com o que pregava. $\mathrm{O}$ ex-combatente não alcançou superar o problema psíquico de experienciar um conflito armado. $\mathrm{Na}$ guerra do Vietnã, alguns monges se imolavam diante de praças em protesto pela invasão. No caso desta personagem, só uma explicação de sua psique afetada poderia levar a um entendimento de seu ato final. Ademais, o depoimento de Buddy, em "Seymour: uma apresentação", que ressalta as suas qualidades excepcionais, é a versão de um irmão admirador. Então, podemos concluir que ele falhou ao não se livrar dos traumas da guerra, ou o Seymour de "Um dia ideal para os peixes-banana" não corresponde ao mesmo das narrativas posteriores, resultando, desta forma, numa falha técnica de Salinger.

\section{REFERÊNCIAS}

FRENCH, Warren. J. D. Salinger. Trad. Rubem Rocha Filho. Rio de Janeiro: Lidador, 1966, p. 174.

GOLDSTEIN, Bernice; GOLDSTEIN, Sanford. The critics. In: WENKE, John. J. D. Salinger: a study of the short fiction. Boston: Twayne Publishers, 1991. p. 160-162.

.Zen and Nine Stories. In: BLOOM, Harold (Org.). J. D. Salinger. New York; New Haven: Philadelphia; Chelsea House Publishers, 1987. p. 81-93.

HAMILTON, Ian. Em busca de J. D. Salinger. Tradução de Adalgisa Campos da Silva. Rio de Janeiro: Casa-Maria Editorial \& LCT - Livros Técnicos e Científicos, 1990.

HENNINGFELD, Anne Gael. Books and more books: reading in J. D. Salinger's Franny and Zooey. Disponível em: <http://www.gradesaver.com/ClassicNotes/Titles/franny/ essays/ essay1.html>. Acesso em: 4 maio 2005.

HESSE, Herman. Sidarta. Tradução de Herbert Caro. São Paulo: Folha de São Paulo, 2003.

LUNDQUIST, James. The critics. In: WENKE, John. J. D. Salinger: a study of the short fiction. Boston: Twayne Publishers, 1991. p. 143-148.

O'CONNOR, Dennis L. J. D. Salinger's religious pluralism: the example of "Raise High the Roof Beam, Carpenters". In: BLOOM, Harold (Org.). J. D. Salinger. New York \& New Haven: Philadelphia \& Chelsea House Publishers, 1987. p. 119-138.

PANICHAS, George. The critics. In: WENKE, John. J. D. Salinger: a study of the short fiction. Boston: Twayne Publishers, 1991. p. 157-159.

PATTANAIK, Dipti R. The holy refusal: a vedantic interpretation of J. D. Salinger's silence. Disponível em: <http://www. findarticles.com/p/articles/mi_m2278/is_2_23/ai_54543100>. Acesso em: 20 set. 2005.

SALINGER, J. D. Carpinteiros, levantem bem alto a cumeeira e Seymour: uma apresentação. Tradução de Jorio 
Dauster. São Paulo: Compahia das Letras, 2001.

Franny \& Zooey. Tradução de Álvaro Cabral. Rio de Janeiro: Editora do Autor, 2003, p. 160.

. Nove estórias. Tradução de Jório Dauster Magalhães e Silva e Álvaro Gurgel de Alencar. Rio de Janeiro: Editora do Autor, 2003.

Hapworth 16, 1924. Disponível em: <http//www. geocities.com/deadcaulfields/stories/Hapworth_16_1925. txt>. Acesso em: 26 set. 2005.

THE WAY of a pilgrim and the pilgrim continue his way. Tradução de Helen Bacovcin. New York: Doubleday, 2003.

WENKE, John. J. D. Salinger: a study of the short fiction.

Boston: Twayne Publishers, 1991, 210 p. 